\title{
Frequency reconfigurable substrate integrated waveguide (SIW) cavity F-shaped slot antenna
}

\author{
Najib AL-Fadhali ${ }^{1}$, Huda A Majid ${ }^{2}$, Rosli Omar ${ }^{3}$, Mohd Hezri Mokhtar ${ }^{4}$, Najmaddin Abo Mosali ${ }^{5}$ \\ ${ }^{1,3}$ Faculty of Electrical and Electronic Engineering, University Tun Hussein Onn Malaysia, Malaysia \\ ${ }^{2,4}$ Faculty of Engineering Technology, University Tun Hussein Onn Malaysia, Malaysia \\ ${ }^{5}$ Faculty of Mechanical and Manufacturing Engineering, University Tun Hussein Onn Malaysia, Malaysia
}

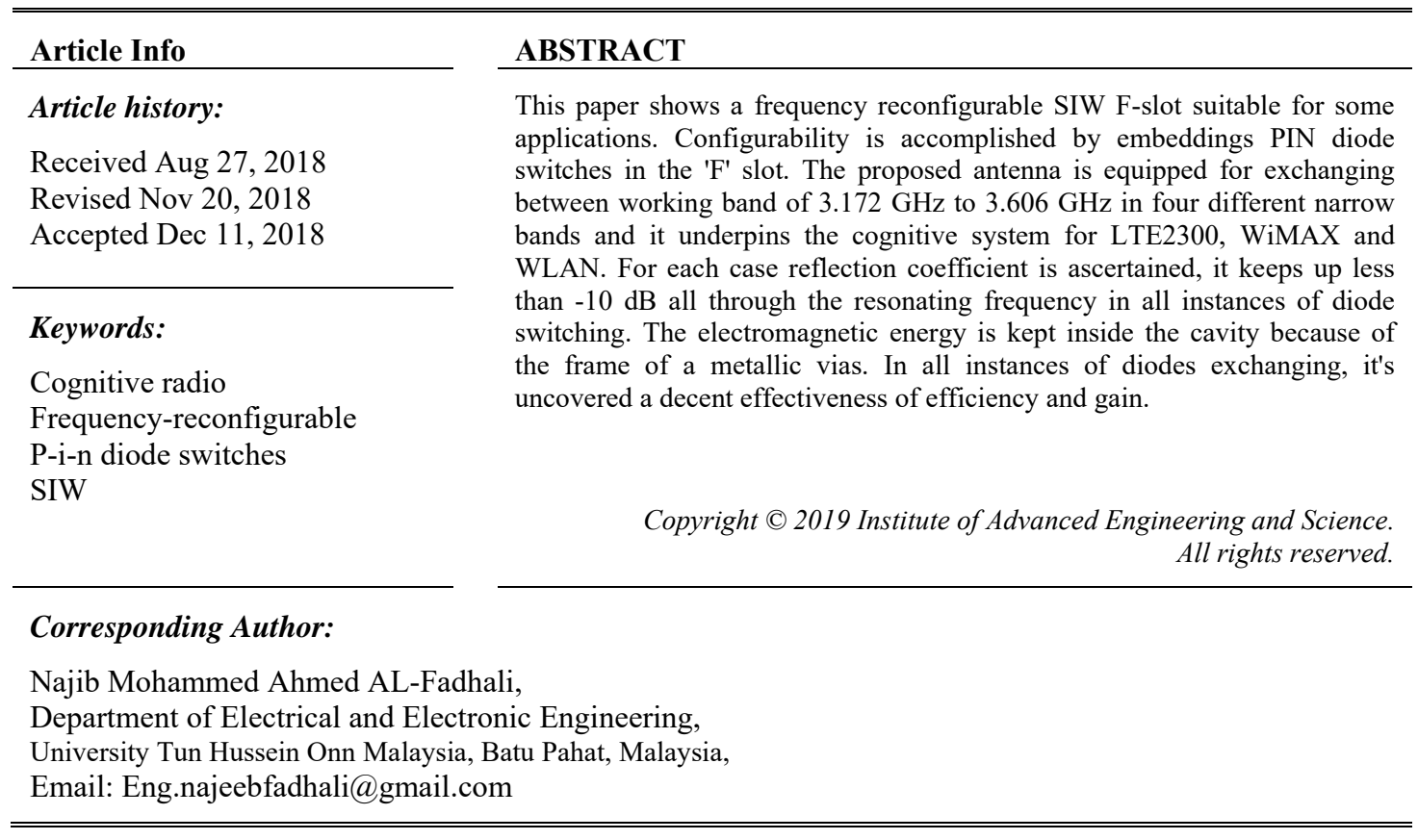

\section{INTRODUCTION}

Currently, reconfigurable techniques are expected to meet the stringent prerequisite of current correspondence to contemporary wirless systems with high performance and conservative size. This has prompted the advancement of complex executions tunable or reconfigurable single or multiband anenna apparatuses that are acknowledged by electric tuning or magnatic tuning [1], [2]. Substrate Integrated Waveguide (SIW) structures include low loss, good power handling of capacity and they can be effectively coordinated with planar circuits [3], [4]. For the most part, the ordinary slot antennas are being utilized for multiband applications yet the detriment of the customary slot antenna apparatuses is two-sided radiation design which settles on them a powerless decision for being utilized on an extra ground plane, such a Printed Circuit Board (PCB), or some other scrambling object. Keeping in mind the end goal to take out the back side radiation, cavity backed slot antennas with high radiation exhibitions seem, by all accounts, to be more agreeable [5]. With the utilization of SIW structures a similar radiation execution of conventional cavity slot antennas can be accomplished alongside the upsides of low profile, simplicity of creation and similarity with planar integration [6]-[8].The SIW innovation is proposed as an elective strategy to encourage the minimal effort usage of waveguide like parts utilizing a standard PCB innovation [9], [10].

The expanding interest for higher data rate and connec-tivity has prompted dynamic range access as the authorized and unlicensed range clients are huge. intelligent antenna which is reconfigurable and changes its working frequency according to the environment is utilized to actualize it. Right now, SIW are turning into an unavoidable decision for the usage of high frequency integrated circuits. SIW is better in comparison with existing stages as far as straightforwardness, light weight and ease. The substrate integrated waveguides (SIW) are rectan-gular waveguides shaped by two strong conveyor planes, isolated by a dielectric substrate, 
with channel sidewalls imitated by lines of metalized through-plated vias[11]. Then again, the SIW sidewalls might be framed by sputtering copper on laser cut troughs in the substrate. The SIW structure is composed by picking fittingly divided vias, all with a similar distance across, to adequately bolster guided wave engendering with at least radiation loss. The dispersing between the vias controls the measure of field spillage out of the waveguide. In the event that the vias are divided too far separated, the confinement property of the SIW will be endangered. This spillage potential sets the confine concerning what modes of propagation are conceivable inside this periodic waveguide.

By reviewing the literature from the previous studies, it was found that a several studies has been used the technique of Frequency reconfigurable substrate-integrated waveguide (FRSIW) technology which is considered to be promising for the development of antennas operating in the microwave and millimeter wavebands because of its characteristics which among others include: low cost; high degree of miniaturization; and ease of installation techniques. However, there is scarcity of research or it can be said that there are not many studies have used this technology in the applications of cognitive communication [11]- [15]. This study aims to use frequency reconfigurable substrate-integrated waveguide (SIW), which is believed that results of this study will significantly improve the miniaturization, antenna performance, increasing the gain as well as radiation pattern. It's believed this study will help academician's research in understanding the effectiveness of Frequency reconfigurable substrate-integrated waveguide (FRSIW) F- slot antenna in terms of E-field radiation and its capability of achieving a reasonable value of efficiency and gain. A distinctive geometry is appeared in Figure 1 where metallic by means of gap clusters function as side dividers of the waveguide while the substrate's metal cover and ground plane form the waveguide broad walls.

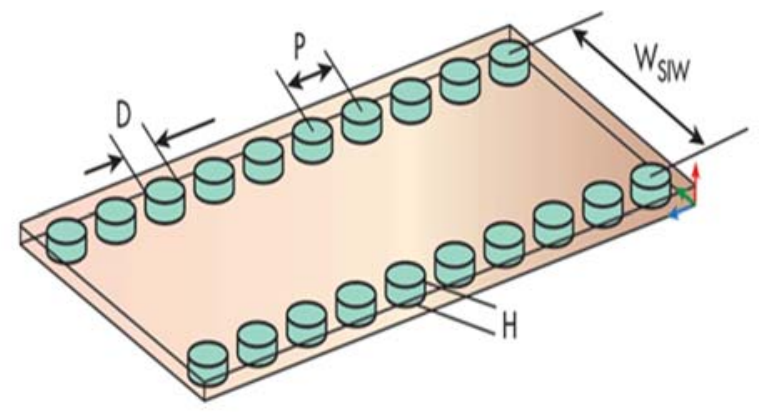

Figure 1. Configuration of the SIW synthesized by metallic via-hole arrays

Setup of the SIW orchestrated by metallic by means of via-hole Arrays as said before, SIW is made out of two parallel varieties of through via holes delimiting the TE10 wave spread zone, as its cutoff frequenc $\mathrm{y}$ is just identified with the width an of the waveguide as long as the substrate thickness or waveguide height ' $\mathrm{b}$ ' is smaller than 'Wsiw'. Parameter 'Wsiw' between the two arrays decides the spread steady of the central $\mathrm{m}$ ode, and parameters of through via holes ' $\mathrm{D}$ ' and ' $\mathrm{p}$ ' are set to limit the radiation loss and in addition the the re turn loss. Despite the fact that SIW can be described by by propagation constant, waveguide mode, cutoff fre quency and guided wavelength like a regular rectangular waveguide, it ought to be noticed that SIW has som e unpleasant physical qualities as compared with traditional rectangular waveguides. Primary, the SIW's geo metrical parameter 'Wsiw' is substantially bigger than ' $b$ ' in light of the fact that there is a physical constraint $t$ o build the substrate thickness ' $b$ '. Second, the comparable waveguide width of SIW, aeff isn't the same as 'W siw'. Along these lines, numerous trials and Reforms have been led to confirm estimation of aeff. One empiri cal condition to ascertain aeff is given by [2].

$$
a_{e f f}=a-1.08 \frac{d^{2}}{p}+0.1 \frac{d^{2}}{a}
$$

Whenever $\mathrm{d} / \mathrm{p}<1 / 3$ and $\mathrm{d} / \mathrm{a}<1 / 5$. SIW can be displayed by rectangular waveguide with a comparab le width and keeps up radiation losses at an insignificant level, when its geometry parameters meet, the metal ized by means of via hole measurement is

Indo. J. Elec. Eng. \& Inf, Vol. 7, No. 1, March 2019: 135 - 142 
$d<\left(\Lambda_{g} / 2\right)$

The distance among the via holes is

$\mathrm{p}<2 \mathrm{~d}$

In overlay Cognitive radio innovation front end of the framework comprise of a sensing antenna app aratus that is a ultra-wideband antenna and a correspondence antenna that is is narrow-band antenna. In this $p$ aper frequency reconfiguration has been demonstrated utilizing SIW F-formed antenna. In the event that an e ssential primary user is allotted in bands and in this, one isn't being utilized, and after that a secondary user ca $\mathrm{n}$ utilize the free band of the primary user. Different antenna situations have been described in the previous st udies [3], [16].

In the following subsequent subsection of this paper section 2 clarifies the antenna geometry and des ign, section 3 designates the simulation results and discussions, and Section 4 concludes the paper.

\section{ANTENNA DESIGN \& ANALYSIS}

The schematic of the proposed antenna is appeared in Figure 2. Which demonstrates the position of the pin diodes, slots in the front, the distance between the consecutive vias, the diameter of via, length and width of the antenna layers.

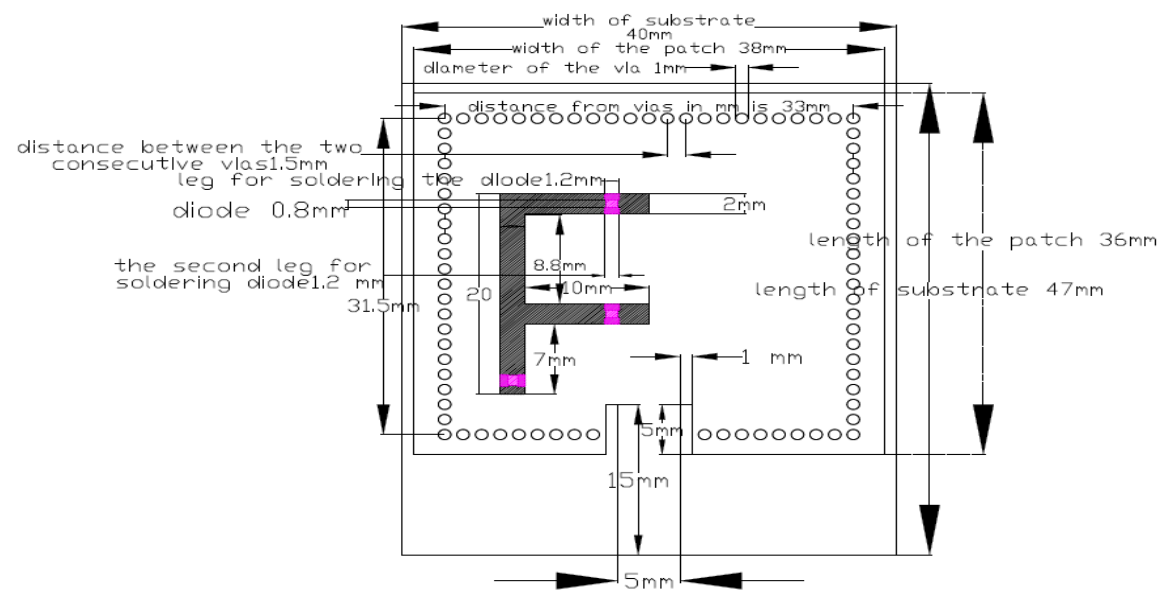

(a)

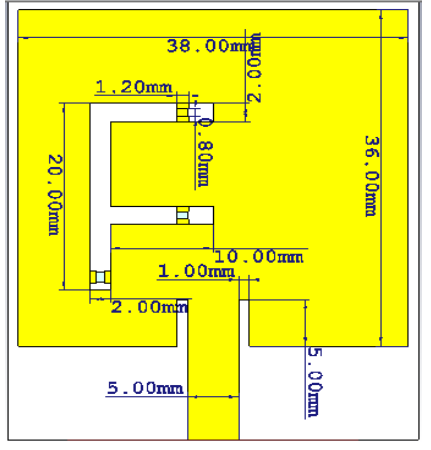

(b)

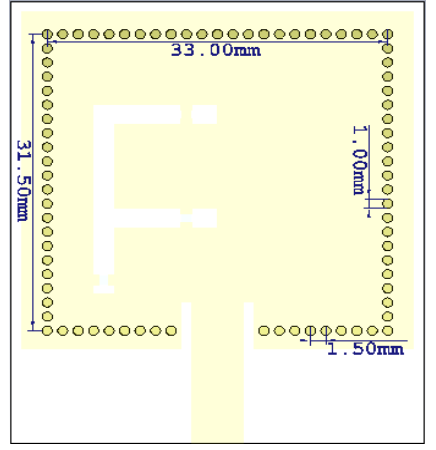

(c)

Figure 2. (a) antenna dimentions details (b) antenna slot dimentions (c) substrate including the vias.

It involves of a radiating element in the form of infront F-shaped slot antenna, fed by a strip line to match the impedance to produce the best return loss at the wanted frequency. The antenna is built on Rogers RT5880 (lossy) with a dielectric constant of 2.2, thickness of $1.27 \mathrm{~mm}$, and loss tangent of 0.0009 . Parameters used in the design are given in Table 1. To achieve frequency configurability, three diodes are symmetrically set on the edges of the F-formed opening and eight electronic switches are set in view of the normal likelihood of changing the 3-Diodes Status as appeared in Table 2 and Figure 2(a).

Frequency reconfigurable substrate integrated waveguide (SIW) cavity F-shaped ... (Najib AL-Fadhali) 
Table 1. The parameters used in the design

\begin{tabular}{|c|c|c|c|}
\hline Parameter Name & Value & Parameter Name & Value \\
\hline Length/width/height of ground respectively & $\begin{array}{l}(47 / 40 / 0.035) \\
\text { millimeter }\end{array}$ & $\begin{array}{l}\text { The length/width/height of legs } \\
\text { that used for diode respectively }\end{array}$ & $\begin{array}{l}(0.6 / 1.2 / 0.035) \\
\text { millimeter }\end{array}$ \\
\hline Length/width/height of substrate & $\begin{array}{l}(47 / 40 / 1.27) \\
\text { millimeter }\end{array}$ & The diode length/width/height & $\begin{array}{c}(0.8 / 1 / 0.035) \\
\text { millimeter }\end{array}$ \\
\hline Length/width/height of strapline & $\begin{array}{l}(10 / 5 / 0.035) \\
\text { millimeter }\end{array}$ & The via dimeter & 1 millimeter \\
\hline Length/width/height of patch & $\begin{array}{l}(36 / 38 / 0.035) \\
\text { millimeter }\end{array}$ & $\begin{array}{l}\text { The distance between the two } \\
\text { consecutive via }\end{array}$ & 1.5 millimeter \\
\hline Length/width/height of feed inset & $\begin{array}{c}(5 / 1 / 0.035) \\
\text { millimeter }\end{array}$ & $\begin{array}{c}\text { The distance between the two } \\
\text { columns of via }\end{array}$ & 33 millimeter \\
\hline Length/width/height of vertical slot of F-shape & $\begin{array}{l}(20 / 2 / 0.035) \\
\text { millimeter }\end{array}$ & $\begin{array}{c}\text { Length/width of horizontal slot of } \\
\text { F-shape }\end{array}$ & $\begin{array}{l}(10 / 2 / 0.035) \\
\text { millimeter }\end{array}$ \\
\hline
\end{tabular}

Table 2. the stats of 3 diodes during achieving the configurability ( 0 for off state and 1 for on state of diode)

\begin{tabular}{ccc}
\hline \multicolumn{3}{c}{ The states of diodes } \\
D1 & D2 & D3 \\
\hline 0 & 0 & 0 \\
0 & 0 & 1 \\
0 & 1 & 0 \\
0 & 1 & 1 \\
1 & 0 & 0 \\
1 & 0 & 1 \\
1 & 1 & 0 \\
1 & 1 & 1 \\
\hline
\end{tabular}

The antenna design and analysis has been done utilizing CST program. The geometry comprises of F-formed space and slots structure to understand the frequency reconfigurable antenna. PIN diodes have been incorporated in the spaces as the exchanging components alongside the biasing system. The place of the PIN diodes has been upgraded keeping in mind the end goal to get less impact on the radiation characteristics. The fundamental favorable position of this geometry is that the structure joins both substrate and cavity to accomplish the less loss and higher productivity.

PIN diode is a semiconductor device that operates as a variable resistor at RF and Microwave frequencies. The resistance of the PIN diode is determined only by forward biased DC current. When the PIN diode is forward bias (ON state) the value of resistance decreases close to $0 \mathrm{ohm}$. The PIN diode is OFF state when it reversed bias.Pin diodes were used to make the antenna resonate at different frequencies. When the diode is ON, it allows the surface current to pass through it, thus making the current Path around the slot shorter. The position of the diodes and the sematic diagram as shown in Figure 3. PIN diode is a semiconductor device that operates as a variable resistor at RF and Microwave frequencies. The resistance of the PIN diode is determined only by forward biased DC current. When the PIN diode is forward bias (ON state) the value of resistance decreases close to $0 \mathrm{ohm}$. The PIN diode is OFF state when it reversed bias. BAR50-02V PIN diode is used in this work as it offers large operating frequency range from $10 \mathrm{MHz}$ to 6 $\mathrm{GHz}$, low forward resistance and low capacitance at zero reverse voltage. The PIN diode is useful especially for RF and microwave devices in wireless communication application. The diode maximum reverse voltage is $50 \mathrm{~V}$ while the maximum forward current of the diode is $100 \mathrm{~mA}$. Figure 3 (b) illustrates the PIN diode BAR50-02V SCD package where port 1 is the cathode and port 2 is the anode. The S-parameter data of the diode can be downloaded from the manufacturer website.

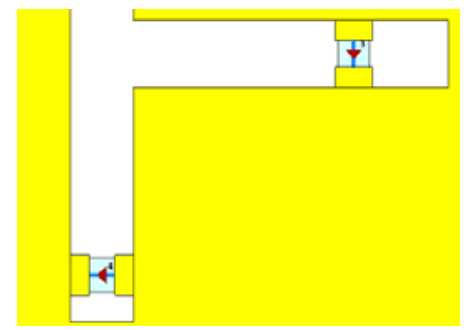

(a)

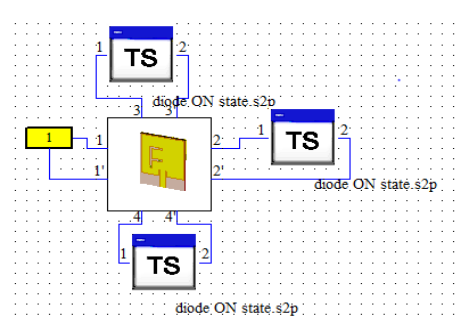

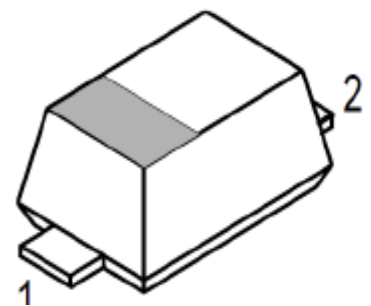

(b)

Figure 3. (a) Circuit simulation using CST software (b) PIN diode BAR50-02V 
In circuit simulation, external port and touchstone block (TS) is inserted and connected to the antenna block. Differential port needs to be set for external port and antenna block. Figure 3 (a) shows the circuit simulation in CST. The S-parameter of the PIN diode is set in the touchstone block. In this example, port 2,3,4 of the antenna block is the PIN diode while port 1 of the antenna block is the waveguide port where it feeds the SIW.

\section{SIMULATION RESULTS AND DISCUSSIONS}

Performance of proposed antenna was researched by utilizing the CST Microwave Studio programming. The streamlined measurement is appeared in Table 1 .Reflection coefficient $(\mathrm{dB})$ demonstrates that in all status of switches are lower - $10 \mathrm{~dB}$ in frequency range $3.172 \mathrm{GHz}$ to $3.606 \mathrm{GHz}$, this condition is utilized to detect range to distinguish holes (unused) frequency bands. The simulated result is shown in Figure 4 which shows the agreement for the four ceases which are $(000 ; 1111 ; 101$ and 010$)$ while, the others cases were ignored due to the effect of overlapping to each other and coffecient reflection were not achevied and therefore have been deleted.

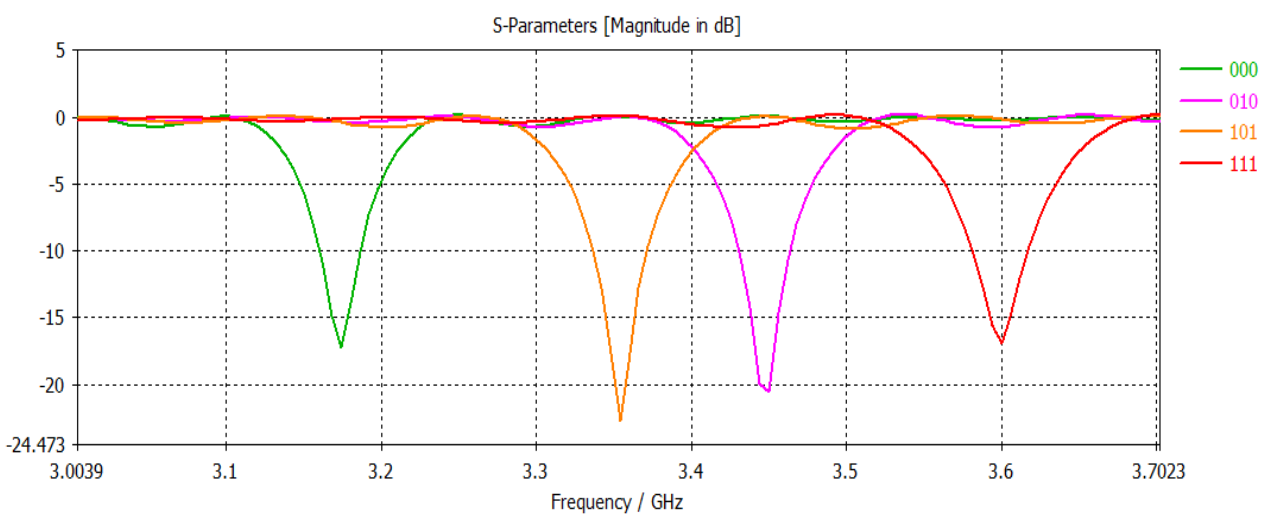

Figure 4. The frequency reconfigurable based on states of diodes

The distribution of the E-field of this antenna for the status of switching shows that it is resonant from the F-slot and the wall of via confined the electromagnetic energy inside the cavity as shown in the figure 5. For this, the current distribution in the slot was studied to determine the maximum current in the slot.The pin diode was placed at the position where the current was maximum.
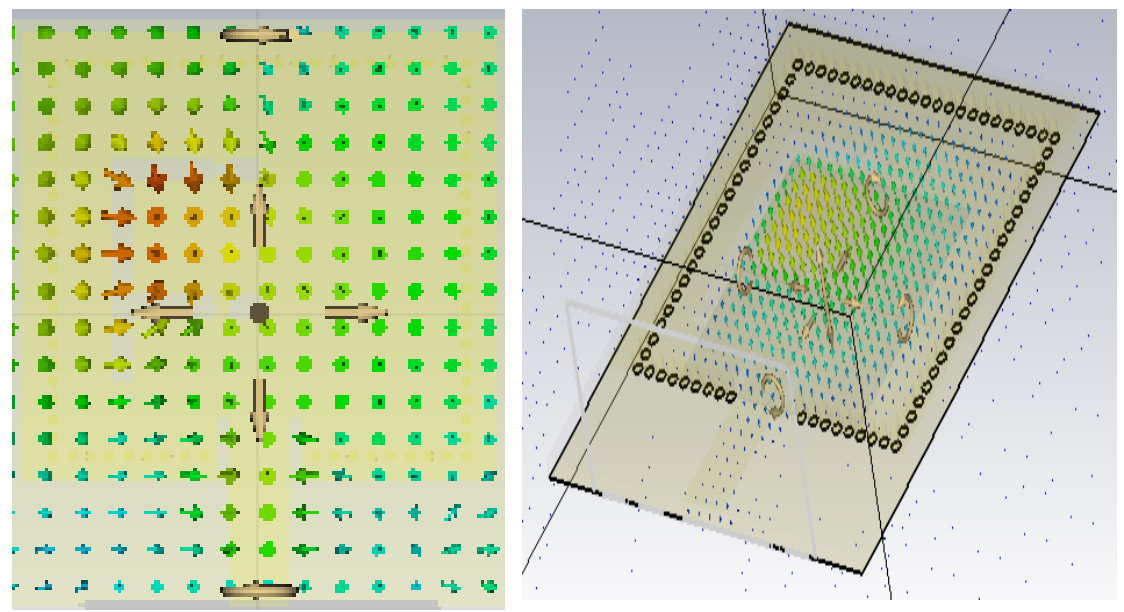

Figure 5. current distribution from cavity slot 
The results of the four states which considered are the case (111) the resonant frequency was at 3.6 $\mathrm{GHz}$ and the refection coefficient below $-10 \mathrm{~dB}$ which recorded $-16.9 \mathrm{~dB}$ which considered a good value to grantee a good matching between the feeding and the patch. The efficiency on the other hand, has been recorded $-3.8 \mathrm{~dB}$.

When state was 000 , the resonant frequency was at $3.174 \mathrm{GHz}$ and the refection coefficient below $10 \mathrm{~dB}$ which recorded $-17.72 \mathrm{~dB}$ which considered a good value to grantee a good matching between the strapline and the patch. The efficiency on the other hand, has been recorded $-3.5 \mathrm{~dB}$.

When state was 101 , the resonant frequency was at $3.354 \mathrm{GHz}$ and the refection coefficient below $10 \mathrm{~dB}$ which recorded $-22.72 \mathrm{~dB}$ which considered a good value to grantee a good matching between the feeder and the patch.The efficiency on the other hand, has been recorded $-3.53 \mathrm{~dB}$.

When state was 010 , the resonant frequency was at $3.45 \mathrm{GHz}$ and the refection coefficient below -10 $\mathrm{dB}$ which recorded $-20.5 \mathrm{~dB}$ which considered a good value to grantee a good matching between the strapline and the patch.The efficiency on the other hand, has been recorded $-3.6 \mathrm{~dB}$.

According to ( [17]-[19]) it can be observed that the Frequency reconfigurable antenna has been extensively employed in wireless communication system applications, especially in Cognitive Radio (CR). Nonetheless, microstrip patch antenna has been reported in the previous literature to suffer from design and biasing complexity, large size of antenna and switching techniques implementation [20]. This paper achieved small size comparing with study of ( [20]-[22] ), where the dimentions were ( $\mathrm{L}=84 \mathrm{~mm}, \mathrm{~W}=84 \mathrm{~mm}, \mathrm{~L}=70$ $\mathrm{mm}, \mathrm{W}=100 \mathrm{~mm}$ and $66 \mathrm{~mm}$ X $90 \mathrm{~mm} \times 1.3 \mathrm{~mm}$ respectively. The proposed antenna reported in this paper decrease about more than $50 \%(38 \mathrm{~mm}$ X $36 \mathrm{~mm})$ of antennas size comparing to the aformentiond recent previous research. Also, the results of this paper improve the results of [23] in terms of complicated design and biasing circuit problem which will be more complicated in implementation. The efficiency obtained from all states are significantly improve the results of [24].

The radiation pattern for all the four states is shown in Figure 6. The radiation is directional for all the states in $\mathrm{E}$ and $\mathrm{H}$ plan. The effectiency greater than $-3.5 \mathrm{~dB}$ for all states.

111 state

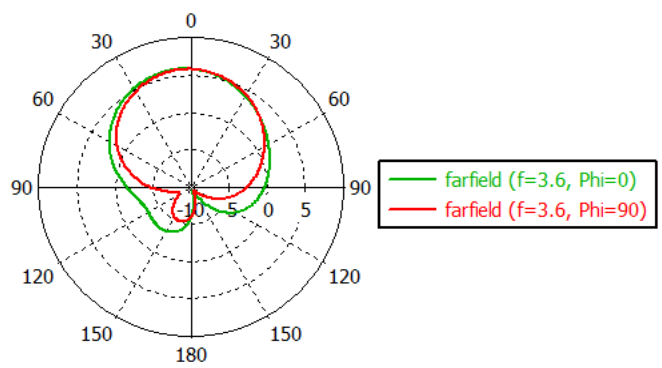

101 state

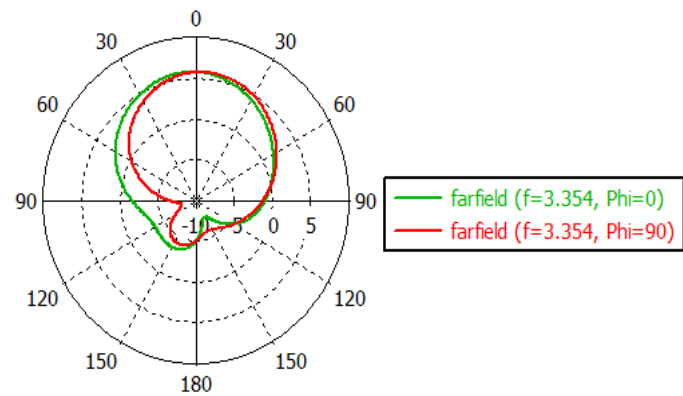

000 state

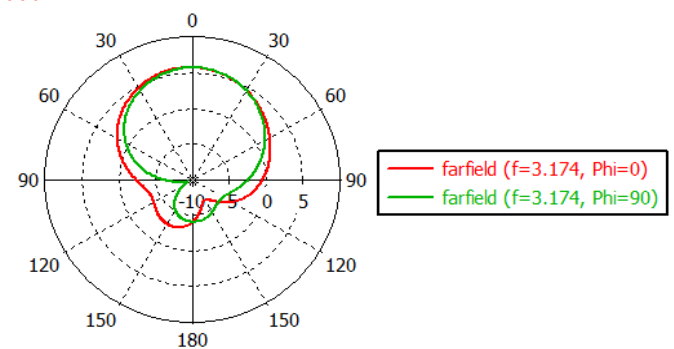

010 state

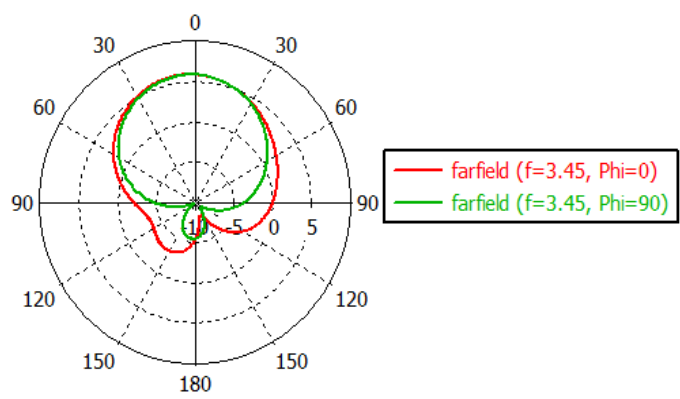

Figure 6. The radiation pattern for all diode states

This paper has some limitations which should be improved in future research such as firstly, the highest efficiency recorded about $-3.5 \mathrm{db}$ and need further improvements. Secondly, the resonating frequencies were in narrowband and need further enhancement and modify the antenna to radiate in multiple band. The authors intend to improve and developing the F-shaped slot SIW antenna to obtain double band to 
serve the cognitive system and cover the improvements of all the limitations stated above. The authors intend to do the fabrication and the required measurments to validate the simulation results in future work.

\section{CONCLUSION}

A frequency reconfigurable SIW F-slot antenna utilizing 3-PIN switches has been considered; Communication bands obtained by properly picking changing conditions from $3.172 \mathrm{GHz}$ to $3.606 \mathrm{GHz}$. It supports cognitive system for WiMax LTE2300, UMTS, Wife as well as WLAN. The proposed antenna demonstrates a decent performance. Radiation efficiency is about more than - $3.6 \mathrm{db}$ for each situation. It is simulated in CST Microwave Studio programming and and the author recommends improving the results of this study as indicated in limitation and recommendation of future work. In future, real-time implementation of pin diodes, fabrication and measurments will be done.

\section{ACKNOWLEDGEMENTS}

This work was supported by Ministry of Higher Education (MOHE), Faculty of Engineering Technology, Research Center of Applied Electromagnetics, Research Management Centre, Universiti Tun Hussein Onn Malaysia (UTHM) under Grant (Vote No).

\section{REFERENCES}

[1] Rabah, et al., "Antennas in Cognitive Radio Systems for 5G Networks: Challenges and Review". In Advanced Wireless Sensing Techniques for 5G Networks. Chapman and Hall/CRC. pp. 181-191, 2018.

[2] Maheshwari, et al., "Design of single and dual band pass filter using substrate integrated waveguide with DGS." Information, Communication, Instrumentation and Control (ICICIC), 2017 IEEE, , pp. 1-5, 2017.

[3] R. lothi and V. Nagarajan "Frequency reconfigurable microstrip antenna using PIN diode" , IEEE Twentieth National Conference on communications (NCC) ,2014 ,pp. 1-4

[4] M. R. Hamid, et al.,"Vivaldi antenna with integrated switch able bandpass resonator",IEEE Trans. Antennas Propagation. vol. 59 (11), pp.4008-4015, Nov 2011.

[5] Ramli, et al., "A Frequency Reconfigurable Stacked Patch Microstrip Antenna (FRSPMA) using PIN diode switch" ECTl-CON, 2013 10th international Conference pp. I - 5.

[6] Nguyen-Trong, et al., "Reconfigurable Half-mode substrate-integrated cavity antenna arrays." 12th European Conference on Antennas and Propagation (EuCAP 2018). IET, pp. 1-4, 2018.

[7] Rodrigues, et al., "Reconfigurable circular ring patch antenna for UWB and cognitive radio applications"Antennas and Propagation (EuCAP), 2014 8th European Conference, pp. 2744 -2748.

[8] Wu, Yongle, et al., "An independently reconfigurable dual-mode dual-band substrate integrated waveguide filter." PloS one, vol. 12(6), pp. 1-13, 2017.

[9] Sam, Weng Yik, and Zahriladha bin Zakaria, "Design of reconfigurable integrated substrate integrated waveguide (SIW) filter and antenna using multilayer approach," International Journal of RF and Microwave Computer-Aided Engineering, vol. 28(9), 2018.

[10] Yan, et al., "Multi-band antenna design for full metal casing mobile handset." 2017 Sixth Asia-Pacific Conference on Antennas and Propagation (APCAP). IEEE, pp. 1-3, 2017.

[11] Singh, and Saini, "Effect of varying curvature and inter element spacing on dielectric coated conformal microstrip antenna array," Progress In Electromagnetics Research, vol. 58, pp. 11-19, 2017.

[12] Peng et al., "Wideband High-Efficiency Filtering SIW Slot Antenna with High Selectivity and Flat Gain Response" International Journal of Antennas and Propagation. Hindawi, vol. 2018, Article ID 3949675, pp. 1-10.

[13] Deckmyn, et al., "Wideband Substrate Integrated Waveguide Antenna for Next-generation mmWave Wireless Systems " EUCAP2018, the 12th European Conference on Antennas and Propagation, pp. 1-4, 2018.

[14] Ali, et al., "Increasing the bandwidth of cavity-backed SIW antennas by using stacked cavities". International Journal of Microwave and Wireless Technologies, vol. 10(8), pp.1-6, 2018.

[15] Rajat Arora, et al., "Performance analysis of Wi-Fi shaped SIW antennas". AEU - International Journal of Electronics and Communications, Elsive, vol. 94, pp. 168-178, 2018.

[16] S. Mohammad-Ali-Nezhad and A. Mallahzadeh, "Periodic ridged leakywave antenna design based on SIW technology," IEEE Antennas Wireless Propag". Letters., vol. 14, pp. 354-357, 2015.

[17] Hussain, Rifaqat, and Mohammad S. Sharawi. "A cognitive radio reconfigurable MIMO and sensing antenna system." IEEE Antennas and Wireless Propagation Letters, vol. 14, pp. 257-260, 2015.

[18] Srivastava, Gunjan, Akhilesh Mohan, and Ajay Chakrabarty. "Compact reconfigurable UWB slot antenna for cognitive radio applications." IEEE Antennas and Wireless Propagation Letters, vol. 16, pp. 1139-1142, 2017.

[19] Joseph, Sumin D., et al. "UWB sensing antenna, reconfigurable transceiver and reconfigurable antenna based cognitive radio test bed." Wireless Personal Communications, vol. 96(3), pp. 3435-3462, 2017.

[20] Mansoul, Ali, and Farid Ghanem. "Frequency reconfigurable antenna for cognitive radios with sequential UWB mode of perception and multiband mode of operation." International Journal of Microwave and Wireless Technologies, pp. 1-7, 2018. 
[21] Zadehparizi, Fatemeh, and Shahrokh Jam. "Frequency reconfigurable antennas design for cognitive radio applications with different number of sub-bands based on genetic algorithm." Wireless Personal Communications, vol. 8(4), pp. 3431-3441, 2018.

[22] Saghati, A. Pourghorban, and Kamran Entesari. "A reconfigurable SIW cavity-backed slot antenna with one octave tuning range." IEEE Trans. Antennas Propag, vol. 61(8), pp. 3937-3945, 2013.

[23] Sharma, Sonia, and Chandra Charu Tripathi. "An Integrated Frequency Reconfigurable Antenna for Cognitive Radio Application." Radioengineering, vol. 26(3), 2017.

[24] Ge, Lei, and Kwai-Man Luk. "Frequency-reconfigurable low-profile circular monopolar patch antenna." IEEE Transactions on Antennas and Propagation, vol. 62(7), pp. 3443-3449.

\section{BIOGRAPHIES OF AUTHORS}
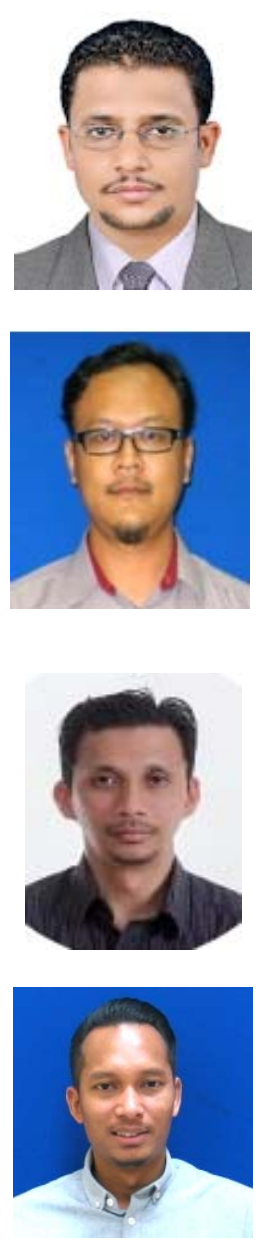

Mohd Hezri Mokhtar received the B Eng. degree in Communication and Computer Engineering from Universiti Kebangsaan Malaysia in 2002. He then obtained his PhD degree in Electronic and Electrical Engineering in 2013 at University of Leeds. He is currently a lecturer in the Department of Mechanical Engineering Technology, Faculty of Engineering Technology, Universiti Tun Hussein Onn Malaysia. His research interest includes ionospheric and upper atmospheric area, space weather, navigation satellite and radio propagation.

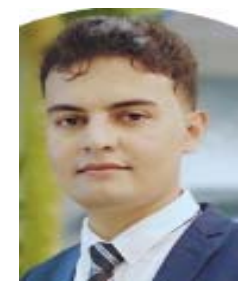

Najmaddin Abo Mosali received the B Eng. degree in Electrical and Electronics Engineering with honours from university tun Hussein onn Malaysia (UTHM) in 2016. Currently, he is a PhD researcher in mechatronics engineering, Universiti Tun Hussein Onn Malaysia. His research interest in area of research which includes the areas of design advanced controllers in UAVs. 